\title{
Core Business Selection Based on Ant Colony Clustering Algorithm
}

\author{
Yu Lan, ${ }^{1}$ Yan Bo, ${ }^{2}$ and Yao Baozhen ${ }^{3}$ \\ ${ }^{1}$ School of International Trade and Commerce, Yanching Institute of Technology, Beijing 065201, China \\ ${ }^{2}$ Transportation Management College, Dalian Maritime University, Dalian 116026, China \\ ${ }^{3}$ School of Automotive Engineering, Dalian University of Technology, Dalian 116024, China \\ Correspondence should be addressed to Yao Baozhen; yaobaozhen@yahoo.cn
}

Received 19 May 2014; Revised 10 July 2014; Accepted 14 July 2014; Published 6 August 2014

Academic Editor: Rui Mu

Copyright (C) $2014 \mathrm{Yu}$ Lan et al. This is an open access article distributed under the Creative Commons Attribution License, which permits unrestricted use, distribution, and reproduction in any medium, provided the original work is properly cited.

Core business is the most important business to the enterprise in diversified business. In this paper, we first introduce the definition and characteristics of the core business and then descript the ant colony clustering algorithm. In order to test the effectiveness of the proposed method, Tianjin Port Logistics Development Co., Ltd. is selected as the research object. Based on the current situation of the development of the company, the core business of the company can be acquired by ant colony clustering algorithm. Thus, the results indicate that the proposed method is an effective way to determine the core business for company.

\section{Introduction}

Core business is the most important business to the enterprise in diversified business. It is the business with the best ability in enterprise management. It has a high added value and the best prospects for development among the enterprise business and can create a relatively high value to the enterprise [1]. Core business decides economic efficiency of enterprises which is closely related to enterprise's strategic positioning. Specifically, the core business is a competitive choice in the intense market competition with related peers [2]. This choice is consistent and associated with the ability and resources of the enterprise. Since the company's resources can be of better and greater use, so the core business has a competitive advantage that noncore businesses do not have and is the key point of the enterprise to stand out among competitors and major source of profit. Development of core business is the big question about the survival of enterprises and the decisive factor in the enterprise based on the market. Meanwhile, the core business is the emphasis and consideration in enterprises continuing strategic positioning [3].

Campbell et al. [4] proposed an alternative frame work guiding core business diversification strategy based on some matching factors. Their results can provide a useful method to guide enterprises to develop their own core business but do not give a specific actionable recognition method based on the above research. For enterprises, it's difficult to find their core business. However, without core business, the enterprises cannot reasonably arrange their corporate resources. Therefore, how to establish the selection method of core business is a very important role to optimize corporate resources and thus improve the level of corporate strategic decisions.

Ant colony algorithm is a newly proposed bionic optimization algorithm, which has unique advantages in solving complex optimization problems [5]. Currently, in the study of algorithms, the study of clustering algorithm based on ant behavior is not much. But, only some studies have shown that behavior-based clustering algorithm can solve complex problems that many traditional clustering algorithms are difficult to resolve and is a promising research direction [616]. This paper introduces the ant colony clustering algorithm into the core business areas and mentions a new selection method of the core business that seeks to get closer to reality and provides a theoretical basis for enterprises to select the core business. The method is calculated by a case, and the results will be compared with those obtained by traditional clustering methods. 


\section{Core Business Segment Indicators}

The company's core business is not the only one and there may be multiple core businesses. American experts have done a survey for the enterprise that had been investigated and studied by Bain Capital [17]. They found that $87 \%$ of the reasons for the enterprise healthy and sustainable development are enterprises having their own core business. But, only three percent of enterprises can have more than three core businesses [18]. Through the analysis of the core business, we can find the direction that enterprises focus on.

2.1. The Extent of the Resource Allocation. Business mainly relies on investment and production to exchange material and information in the community [19]. If the core business can be well developed, then the company's core competencies will be improved. So, leadership is more focus on core business in the enterprise. Companies tend to give priority to the core business when making the allocation of resources, such that the cost of the study will be more willing to invest. But, if there is excessive diversity issue, it will result in disproportionate or unreasonable resource allocation, making noncore businesses wasted resources that should belong to the core business. Enterprise resource has a certain limit and too much business sector will lead to resource misallocation and affect the core competitiveness of the enterprise [20].

2.2. The Contribution of the Enterprise Output. Core business brings together the most outstanding resources of the enterprise and occupies the largest part of human and material resources of corporate [21]. So, the core business will inevitably determine the overall output of the enterprise. Due to the different nature of each industry, the core business will be different, but the core business, without exception, is the business with the largest investment and utilization of resources.

2.3. The Ability to Obtain the Degree. Competitiveness of enterprises mainly comes from the company's core competencies. Core competence is also comprehensive enterprise knowledge. It includes the recessive and dominant ability of enterprises and is the source of enterprises to maintain a competitive advantage in the fierce market competition [22]. Through ability support to the business sector, core competence can make the operating department transform the core ability to their capabilities on the basis of their original. However, for the absorption of core competencies of different business sectors, there are some differences in a certain extent. Different departments have their own absorption capacity, so these differences of ability have led to differentiation in the effect of the business sector [23].

We summarize the characteristics of the core business and obtain segment indicators of core business and we can find that a major feature of the core business is to have a higher share of resources. In most enterprises, the businesses with higher input and a higher proportion of resources also create higher revenue and this is consistent with the second feature of the core business. The best indicator to

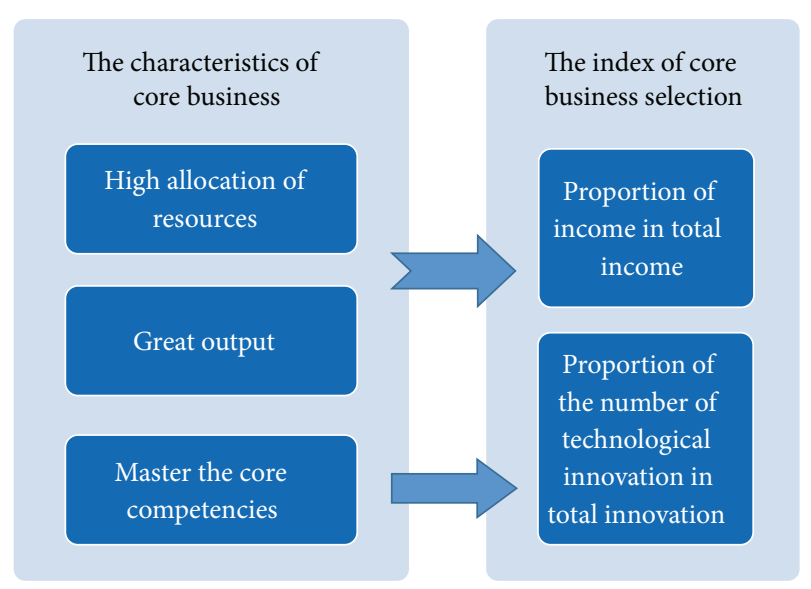

FIGURE 1: The derivation process of segment indicators.

measure the extent of a business in revenue contribution is the proportion of income in total income of this business. The third characteristic of the core business is that it can access competitiveness better. In today's competitive environment, the key to competitive advantage lies in innovation. Therefore, the key to measure whether a business is core business is to evaluate whether the business is innovative, specifically, is the proportion of the number of technological innovation in total innovation. We select proportion of the number of technological innovations in total innovation and proportion of income in total income as the main factors influencing the choice of the core business. This process is shown in Figure 1.

\section{Ant Colony Clustering Algorithm}

The inspiration of ant colony clustering algorithm derived from the ants piled their corpses and classification of their larvae. Deneubourg et al. [24] were enlightened by the behavior of ant colony classified ant eggs and firstly proposed the ant colony clustering algorithm. In the algorithm, the robot imitates the behavior of ants to identify two different objects. Thus, according to the similarity of data objects and their surrounding objects, ants move randomly, picking up or dropping data objects, in order to achieve the purpose of data clustering, and this model is successfully applied to the field of robotics. Thereafter, Lumer and Faieta [25], Ramos and Merelo, and so forth [26] carried out some research in this area and got some successful experience. Although the study of ant colony clustering algorithm is not a lot, but preliminary studies [27-29] have shown that the algorithm is a good clustering algorithm and can be applied to complex clustering problem in many areas of engineering.

In order to carry out the algorithm description, we introduce the basic principle of the algorithm. First, the data is randomly projected onto a target plane, and then select a data object to each ant randomly. According to the probability obtained from the similarity of object in the local area, determine whether the ants pick up, putdown, or move object. After a limited number of iterations, the data objects on the plane are aggregating according to their similarity to give the final clustering result. 
(1) The number of individual ants is $N$; maximum number of iterations is $M$; side length of localized area is $s$; velocity of ants, $v$, takes a random number.

(2) The data object is projected onto a plane and each object is assigned a point $(x, y)$.

(3) Each ant is initialized to unload and randomly selects an object.

(4) for $i=1,2, \ldots, M$ for $j=1,2, \ldots, N$

Calculate the average similarity of object.

If the antis unloaded, then calculate the probability of picking up, $P_{p}$. If $P_{p}$ is greater than a random probability, while on the same time the object is not being picked up by other ants, the ant picks up the object and moves elsewhere randomly, and marks that it is load; otherwise, the ant refuses to pick up the object and selects other objects randomly.

If the antis loaded, then calculate the probability of putting down, $P_{d}$. If $P_{d}$ is greater than a random probability, the ant puts down the object and marks that it is unload, and then re-select a new object. Otherwise, the ant continues to move the object to a new location.

End

(5) for $i=1,2, \ldots, N$

If an object is isolated or the number of its neighborhood is less than a certain constant, then mark the object as an isolated point; otherwise, the object is assigned to a cluster serial number, and recursively their neighborhood object tag for the same serial number.

End

Pseudocode 1

Pseudocode of basic process of algorithm is as shown in Pseudocode 1.

3.1. Calculation of the Average Similarity. Assuming an ant found the data object $o_{i}$ at time $t$ in placer, the average similarity of object $o_{i}$ and its neighborhood object $o_{j}$ is calculated by the following formula:

$$
\begin{aligned}
& f\left(o_{i}\right) \\
& \quad=\max \left\{0, \frac{1}{s^{2}} \sum_{o_{j} \in \operatorname{Neigh}_{s \times s}(r)}\left[1-\frac{d\left(o_{i}, o_{j}\right)}{\alpha\left(1+(v-1) / v_{\max }\right)}\right]\right\},
\end{aligned}
$$

where $\alpha$ is a similarity parameter; $v$ is the speed of ants; $v_{\max }$ is the maximum speed; Neigh $\operatorname{s\times s}_{(}(r)$ is a square of side length $s$ of the local area around place $r . d\left(o_{i}, o_{j}\right)$ represents the distance between $o_{i}$ and $o_{j}$ in the property space. $\alpha$ is the parameter to adjust the similarity between data, and it also determines the number of clusters and the speed of convergence. The larger the $\alpha$ is, the greater the degree of similarity between objects is, the fewer the number of clustering is, and the faster the convergence is. This also may make different objects classified as a class. On the contrary, the smaller the $\alpha$ is, the smaller the degree of similarity between objects is. In extreme cases, a big category can be divided into many small categories while increasing the number of clusters and slowing down the convergence. Thus, in the actual calculation, $\alpha$ should be determined by experience or trial. In addition, the movement speed of the ants also influences the effect of clustering. The faster ants can roughly divide the objects into large categories, the slower ants can more accurately divide the objects. In this article, in order to facilitate the study, ants speed is set to a random number from 1 to $v_{\max }$.
3.2. Calculation of the Probability Conversion Function. Probability conversion function is a function about $f\left(o_{i}\right)$. It converts the average similarity of data objects into the probability of picking up or putting down. Conversion principle is the smaller the average similarity of data objects and their neighborhood is, the smaller the possibility of data object that belongs to this neighborhood is, the higher the probability of picking up is, and the lower the probability of putting down is, and vice versa. According to this principle, the symmetric Sigmoid function is selected as probability conversion function:

$$
\operatorname{Sigmoid}\left(f\left(o_{i}\right)\right)=\frac{1-e^{-c x}}{1+e^{-c x}} .
$$

The probability of an ant that is unloaded and move randomly picking up an object is defined as

$$
P_{p}=1-\operatorname{Sigmoid}\left(f\left(o_{i}\right)\right) \text {. }
$$

Similarly, the probability of an ant that is loaded and moves randomly putting down an object is defined as

$$
P_{d}=\operatorname{Sigmoid}\left(f\left(o_{i}\right)\right) .
$$

It should be noted that in the process of clustering, some objects called isolated points are not similar to other objects. Once the ants pick them up, it is hard to put them down as soon as possible, which affects the convergence speed. Here, we increase the value of $c$ in the latter algorithm to lay down the isolated points as soon as possible.

\section{Computational Experiments}

4.1. Brief Introduction of Tianjin Port Logistics Development Co., Ltd. Tianjin Port Logistics Development Co., Ltd. was 
established in April 1, 2009 with a registered capital of 667 million yuan and 2,800 employees. The company has the ability yard area of nearly 1.2 million square meters, the distance between the marina and the main was less than three kilometers, and stockpiling even reached 40,000 TEUs. The company has a dedicated railway line which is up to 4080 meters and seven dedicated rail line of sea. Thus, railway transportation can be expanded. Because of the structure of dry port, the functions of port are even extended to the hinterland of the city. By this barrier-free access between the port and the hinterland, the company is able to provide customers with good service in domestic shipping, freight forwarding, handling, and other logistics services. On the basis of the excellent resources on the port, combining with the function of the dock, Port Group company continued to attract a variety of integrated logistics resources; its type of business has covered shipping agency, freight forwarding, warehousing and transportation, bonded logistics, large logistics and warehouse receipts pledge, marine insurance, and other related logistics financial services; and with a number of shipping companies and land transport company it established a strategic alliance, into a port logistics featuring large-scale comprehensive logistics enterprises. Tianjin Port Logistics Development Co., Ltd. adheres to the market demand, through the use of information networks, building up the whole process of the logistics network platform. On the basis of full understanding of industry characteristics, company further optimizes resource allocation, enhances service competitiveness, and strengthens marketing force, and with good logistics infrastructure, advantages of port resources, and efficient operation of the team and good service system, dedicated to providing our customers with better quality, modern logistics services.

Table 1 selects ten businesses that Tianjin Port Logistics Development Co., Ltd. is mainly engaged in. From the data in the table, we can see that the profit of domestic cargo agents, pier horizontal transport, container yard operations, and automotive logistics are the biggest. To Tianjin Port Logistics Development Co., Ltd., such a logistic service enterprise without actual output products, revenue is the basis of corporate survival. Therefore, it can be concluded from the data in the table that domestic cargo agents, pier horizontal transport, container yard operations, and automotive logistics are core businesses in Tianjin Port Logistics Development Co., Ltd.

4.2. Cluster Calculation of Sample Enterprises. According to the results of the second chapter, we select proportion of the number of technological innovations in total innovation and proportion of income in total income as the main factors influencing the choice of the core business. Relevant data are shown in Table 1. In order to characterize the importance of the business, the business is divided into four levels, namely, core business, potential core business, integrated business, abd recession business. They are represented as 1, 2, 3, and 4 in the calculation.

Using ant colony clustering algorithm to calculate sample examples in Table 1, algorithm parameters of calculation take the value as follows: the number of individuals of ants, $N$, is
Table 1: Tianjin Port Logistics Development Co., Ltd. patent and business income proportion table.

\begin{tabular}{lcc}
\hline Project & $\begin{array}{c}\text { Proportion of the } \\
\text { number of } \\
\text { technological } \\
\text { innovation in } \\
\text { totalinnovation }\end{array}$ & $\begin{array}{c}\text { Proportion of } \\
\text { income in total } \\
\text { income }\end{array}$ \\
\hline $\begin{array}{l}\text { Domestic shipping } \\
\text { and cargo agents }\end{array}$ & 0 & $27.3 \%$ \\
$\begin{array}{l}\text { International shipping } \\
\text { and cargo agents }\end{array}$ & 0 & $0.56 \%$ \\
$\begin{array}{l}\text { Pier horizontal } \\
\text { transport }\end{array}$ & $30 \%$ & $20.5 \%$ \\
$\begin{array}{l}\text { Container yard } \\
\text { operations }\end{array}$ & $35 \%$ & $37.1 \%$ \\
$\begin{array}{l}\text { Customs clearance } \\
\text { Multimodal } \\
\text { transportation }\end{array}$ & 0 & $0.56 \%$ \\
$\begin{array}{l}\text { Automotive logistics } \\
\text { Bonded logistics }\end{array}$ & $5 \%$ & $1.4 \%$ \\
$\begin{array}{l}\text { Project logistics } \\
\text { Hazardous material } \\
\text { logistics }\end{array}$ & $1 \%$ & $10 \%$ \\
\hline
\end{tabular}

TABLE 2: Computed results.

\begin{tabular}{lcc}
\hline Project & \multicolumn{2}{c}{ Result } \\
& $\begin{array}{c}\text { Conventional } \\
\text { clustering }\end{array}$ & Ant clustering \\
\hline $\begin{array}{l}\text { Domestic shipping and cargo } \\
\text { agents }\end{array}$ & 3 & 3 \\
$\begin{array}{l}\text { International shipping and } \\
\text { cargo agents }\end{array}$ & 4 & 4 \\
Pier horizontal transport & 2 & 1 \\
Container yard operations & 1 & 1 \\
Customs clearance & 4 & 4 \\
Multimodal transportation & 3 & 3 \\
Automotive logistics & 3 & 2 \\
Bonded logistics & 2 & 2 \\
Project logistics & 3 & 3 \\
Hazardous material logistics & 2 & \\
\hline
\end{tabular}

10 ; the maximum number of iterations, $M$, is taken as 2000 ; similarity parameter, $\alpha$, is taken as 1.5 ; the maximum speed of ants, $v_{\max }$, is taken as 0.8 ; length of local area, $s$, is taken as 2 ; the parameter in the probability transfer function, $c$, is taken as 3 .

Under these conditions, the results are shown in Table 2. For comparison, the calculated results of conventional clustering method are also shown in Table 2.

According to the results of Table 2, the company's core businesses are container yard business and pier horizontal transport business; potential core businesses are automotive logistics, bonded logistics, and project logistics; integrated 
businesses are domestic shipping and cargo agents, multimodal transportation and hazardous material logistics; recession businesses are international shipping and cargo agents and customs clearance.

4.3. Comparative Analyses. Through the analysis of Table 2, we can find that the result obtained by the ant colony clustering algorithm and the result obtained by the conventional clustering algorithm are basically the same. But, the result obtained by the ant colony clustering algorithm is more consistent with the basic situation of enterprises.

Conventional clustering algorithm needs to determine cluster centers in advance and there are strict requirements for input order of sample. As a local search algorithm, it cannot handle local minima problems. Therefore, when the initial cluster centers in the whole sample space are imbalanced, it is difficult to rectify this imbalance. As a new bionic algorithm, ant colony clustering algorithm does not have these questions. Visibly, ant colony clustering algorithm is a good analysis algorithm with broad applicability and higher accuracy.

\section{Conclusions}

This paper described the concept and characteristics of the core business, selects Tianjin Port Logistics Development Co., Ltd. as the research objects, and uses SVM method to analyze ten main businesses of Tianjin Port Logistics Development Co., Ltd. Finally, we come to the core business of Tianjin Port Logistics Development Co., Ltd.: container yard business, domestic ship and cargo agency business, pier horizontal transport business. There, our contribution is attempted to use ant colony clustering algorithm to solve the core business selection and provide a new method for researchers and producers.

Although we achieved the expected results in the research of the core business choice of Tianjin Port Logistics Development Co, Ltd., there are still some limitations on this study because of the complexity, variability, and unpredictable nature of the internal and external environment and the restriction of paper length and the author's own level. And the case used in this paper is relatively simple, too. Therefore, more sophisticated scenario needs to be further studied in our future work.

\section{Conflict of Interests}

The authors declare that there is no conflict of interests regarding the publication of this paper.

\section{Acknowledgments}

This work was supported by National Natural Science Foundation of China 51208079, the Fundamental Research Funds for the Central Universities 3013-852019, and the help from Dr. B. YU from School of Traffic and Transportation, Beijing Jiaotong University, and Dr. L.P. Zhou from Wuxi Mingda Traffic \& Technology Consulted Co., Ltd.

\section{References}

[1] C. K. Prahalad and G. Hamel, The Core Competence of the Corporation, Harvard Business Review, 1990.

[2] U. Arnold, "New dimensions of outsourcing: a combination of transaction cost economics and the core competencies concept," European Journal of Purchasing and Supply Management, vol. 6, no. 1, pp. 23-29, 2000.

[3] G. Michael and L. Kathleen, "Why diversify? Four decades of management thinking," Executive, vol. 7, no. 3, pp. 7-25, 1993.

[4] A. Campbell, M. Goold, and M. Alexander, Corperate Strategy: The Quest for Parenting Advantage, Harvard Business Review, 1995.

[5] M. Dorigo, V. Maniezzo, and A. Colorni, "Ant system: optimization by a colony of cooperating agents," IEEE Transactions on Systems, Man, and Cybernetics, Part B: Cybernetics, vol. 26, no. 1, pp. 29-41, 1996.

[6] B. Yao, C. Yang, J. Yao, and J. Sun, "Tunnel surrounding rock displacement prediction using support vector machine," International Journal of Computational Intelligence Systems, vol. 3, no. 6, pp. 843-852, 2010.

[7] B. Z. Yao, J. B. Yao, M. H. Zhang, and L. Yu, "Improved support vector machine regression in multi-step-ahead prediction for rock displacement surrounding a tunnel," Scientia Iranica, accepted, 2013.

[8] B. Yu, Z. Yang, and K. Chen, "Hybrid model for prediction of bus arrival times at next station," Journal of Advanced Transportation, vol. 44, no. 3, pp. 193-204, 2010.

[9] B. Yu, Z. Yang, and S. Li, "Real-time partway deadheading strategy based on transit service reliability assessment," Transportation Research A: Policy and Practice, vol. 46, no. 8, pp. 12651279, 2012.

[10] B. Yu, T. Ye, X.-M. Tian, G.-B. Ning, and S.-Q. Zhong, "Bus travel-time prediction with forgetting factor," Journal of Computing in Civil Engineering, vol. 28, no. 3, 2012.

[11] B. Z. Yao, P. Hu, X. H. Lu, J. J. Gao, and M. H. Zhang, “Transit network design based on travel time reliability," Transportation Research C, vol. 43, pp. 233-248, 2014.

[12] B. Yao, P. Hu, M. Zhang, and S. Wang, "Artificial bee colony algorithm with scanning strategy for the periodic vehicle routing problem," Simulation, vol. 89, no. 6, pp. 762-770, 2013.

[13] B. Z. Yao, P. Hu, M. H. Zhang, and X. M. Tian, "Improved ant colony optimization for seafood product delivery routing problem," PROMET-TRAFFIC \& Transportation, vol. 26, no. 1, pp. 1-10, 2014.

[14] B. Yu, Z. Yang, and J. Yao, "Genetic algorithm for bus frequency optimization," Journal of Transportation Engineering, vol. 136, no. 6, pp. 576-583, 2010.

[15] B. Yu, Z. Z. Yang, and B. Z. Yao, "A hybrid algorithm for vehicle routing problem with time windows," Expert Systems with Applications, vol. 38, no. 1, pp. 435-441, 2011.

[16] B. Yu, H. B. Zhu, W. J. Cai, N. Ma, Q. Kuang, and B. Z. Yao, “Twophase optimization approach to transit hub location-the case of Dalian," Journal of Transport Geography, vol. 33, pp. 62-71, 2013.

[17] C. K. Prahalad, "The role of core competence in the corporation," Research Technology Management, pp. 40-47, 1993.

[18] C. Zook and J. Allen, Main Profit, CITIC Publishing House, Beijing, China, 2002.

[19] G. Hamel, "Competition for competence and inter-partner learning within international strategic alliances," Strategic Management Journal, vol. 12, pp. 83-100, 1991. 
[20] E. P. Przybylowiez and T. W. Faulkner, "Kodak applies strategic intent to the management of technology," Researeh Technology Management, no. 1, pp. 31-38, 1993.

[21] G. Hnaje and C. K. Prahalad, Competing for the Future, Harvard Business School Press, Cambridge, Mass, USA, 1994.

[22] D. Klostad, M. Kesler, and W. E. Clarke, "Third generation R\&D: the key to leveraging core competencies," The Columbia Journal of World Business, vol. 28, no. 3, p. 34, 1993.

[23] R. E. Stake, "Case studies," in Handbook of Qualitative Research, N. K. Denzin and Y. S. Lineoln, Eds., pp. 435-454, Sage, Thousand Oaks, Calif, USA, 2000.

[24] J. L. Deneubourg, S. Goss, N. Franks et al., "Thedynamics of collective sorting: robot-like ant and ant-likerobot," in Proceedings 1st Conference on Simulation of Adaptive Bhavior: From Animals to Animats, pp. 356-365, MIT Press, Cambridge, Mass, USA, 1991.

[25] E. Lumer and B. Faieta, "Diversity and adaptation inpopulations of clustering ants," in Proceedings of the 3rd International Conference on Simulation of Adaptive Behavior: From Animals to Animats, pp. 499-508, MIT Press, Cambridge, Mass, USA, 1994.

[26] V. Ramos and J. J. Merelo, "Self-organized stigmergicdocument maps: environment as a mechanism for context learning," in Proceedings of the 1st Spanish Conference on Evolutionary and Bio-Inspired Algorithms (AEB '02), pp. 284-293, Mérida, Spain, 2002.

[27] M. Reed, A. Yiannakou, and R. Evering, "An ant colony algorithm for the multi-compartment vehicle routing problem," Applied Soft Computing, vol. 15, pp. 169-176, 2014.

[28] J. Wang, A. Tu, and H. Huang, "An ant colony clustering algorithm improved from ATTA," Physics Procedia B, vol. 24, pp. 1414-1421, 2012.

[29] J. Ji, X. Song, C. Liu, and X. Zhang, "Ant colony clustering with fitness perception and pheromone diffusion for community detection in complex networks," Physica A: Statistical Mechanics and its Applications, vol. 392, no. 15, pp. 3260-3272, 2013. 


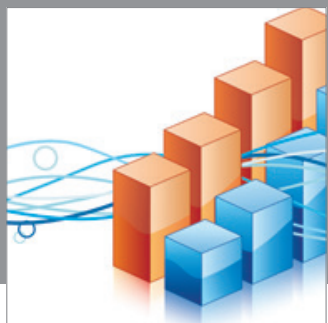

Advances in

Operations Research

mansans

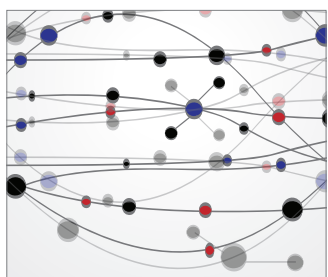

The Scientific World Journal
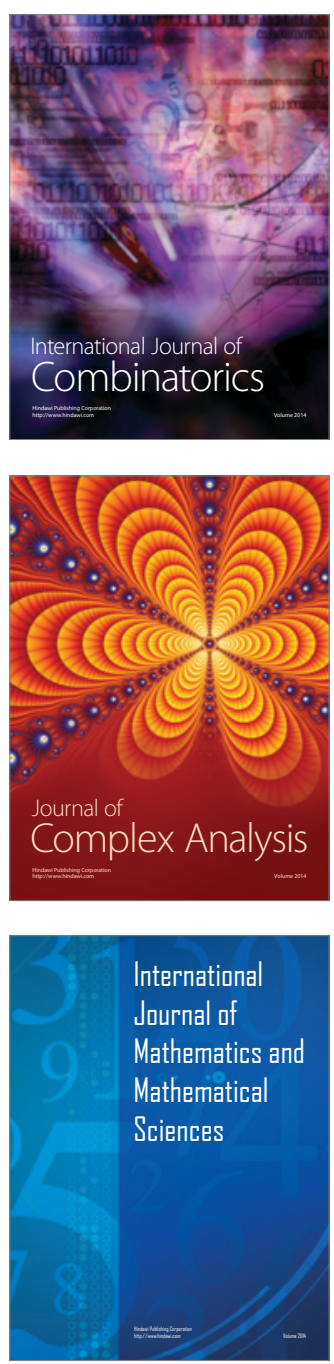
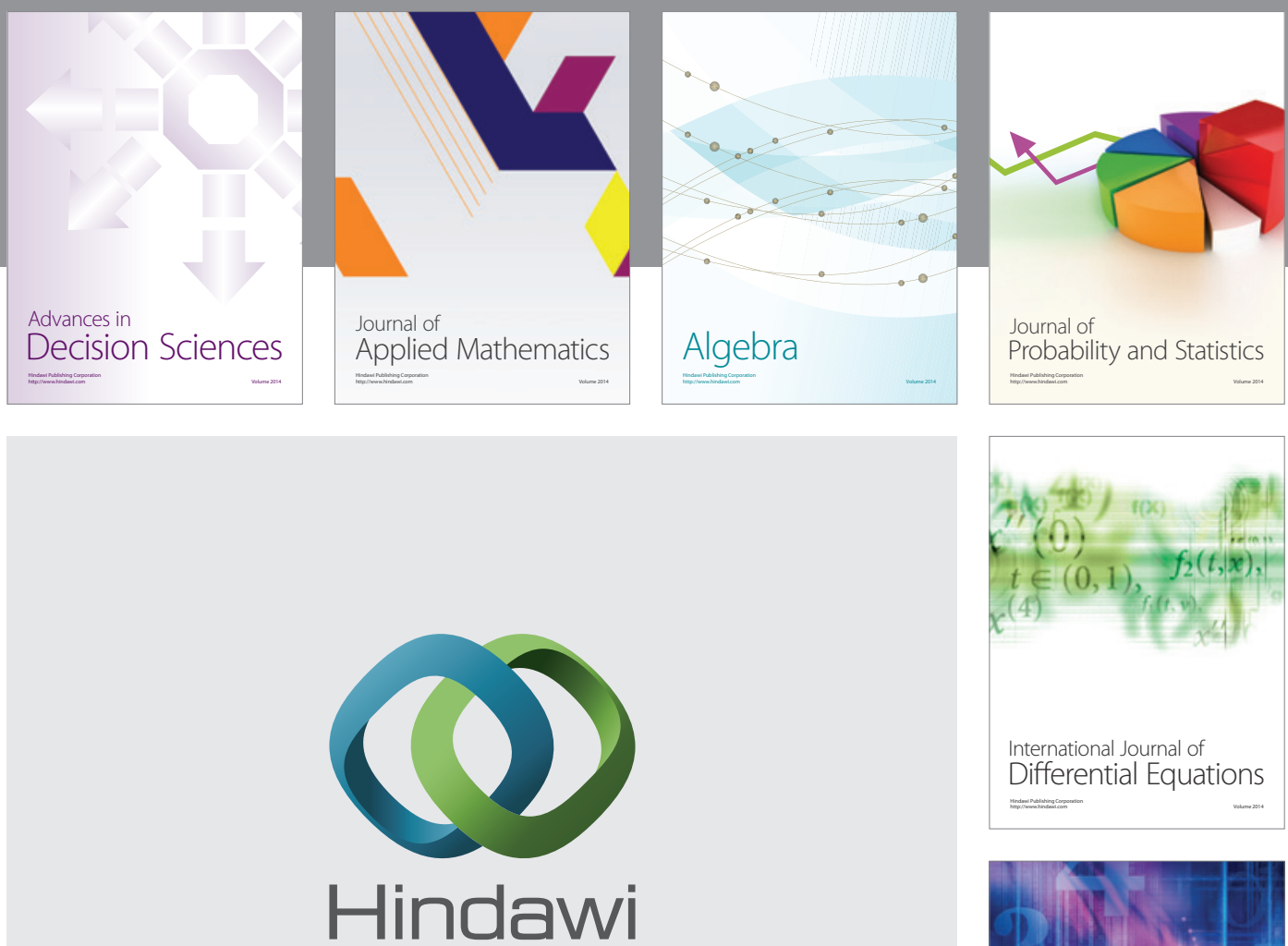

Submit your manuscripts at http://www.hindawi.com
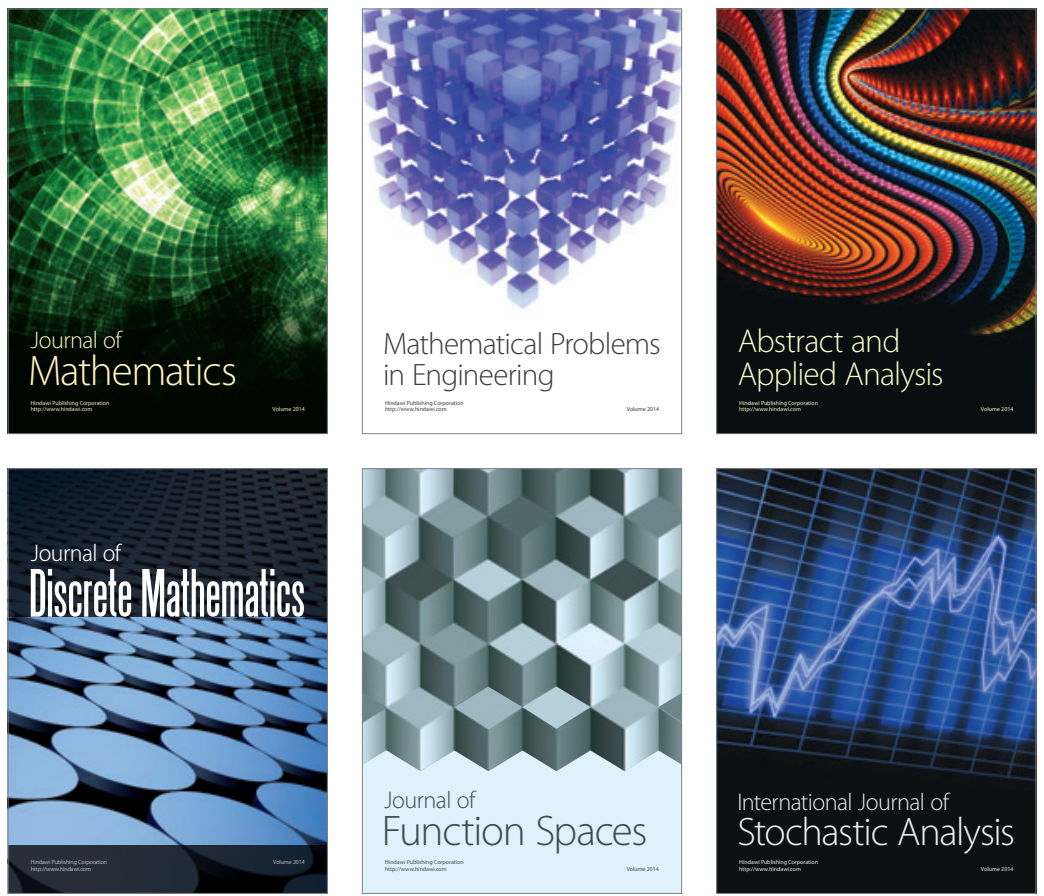

Journal of

Function Spaces

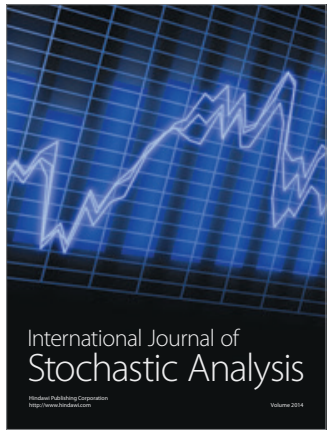

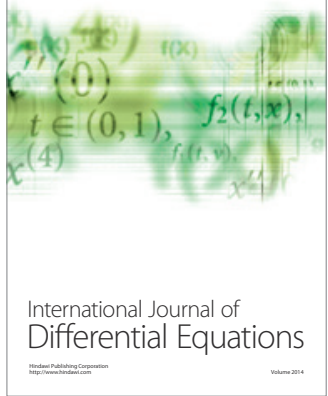
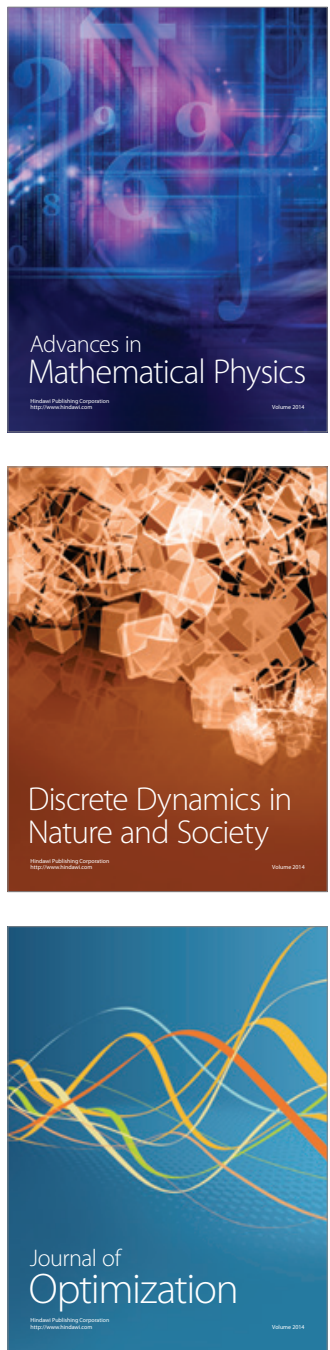